\title{
Winners and losers over 35 years of dragonfly and damselfly distributional change in Germany
}

\author{
Diana E. Bowler ${ }^{1,2,3}$ (D) | David Eichenberg ${ }^{1}$ (D) | Klaus-Jürgen Conze ${ }^{4}$ | Frank Suhling \\ Kathrin Baumann ${ }^{6}$ | Theodor Benken ${ }^{7}$ | André Bönsel $^{8}$ | Torsten Bittner ${ }^{9}$ | \\ Arne Drews $^{10}$ | André Günther ${ }^{11}$ | Nick J.B. Isaac ${ }^{12}$ (D) | Falk Petzold ${ }^{13}$ | \\ Marcel Seyring $^{14}$ | Torsten Spengler ${ }^{6}$ | Bernd Trockur ${ }^{15}$ | Christoph Willigalla ${ }^{16}$ | \\ Helge Bruelheide ${ }^{1,17}$ (i) | Florian Jansen ${ }^{18}$ (D) | Aletta Bonn ${ }^{1,2,3}$ (i) \\ ${ }^{1}$ German Centre for Integrative Biodiversity Research (iDiv) Halle-Jena-Leipzig, Leipzig, Germany \\ ${ }^{2}$ Institute of Biodiversity, Friedrich Schiller University Jena, Jena, Germany \\ ${ }^{3}$ Department Ecosystem Services, Helmholtz-Center for Environmental Research - UFZ, Leipzig, Germany \\ ${ }^{4} \mathrm{GdO}$ (Gesellschaft deutschsprachiger Odonatologen) \& Arbeitskreis Libellen NRW, Essen, Germany \\ ${ }^{5}$ Department Landscape Ecology and Environmental Systems Analysis, Institute of Geoecology, Technische Universität Braunschweig, Braunschweig, Germany \\ ${ }^{6}$ Arbeitsgemeinschaft Libellen in Niedersachsen und Bremen, Niedersachsen and Bremen, Germany \\ ${ }^{7}$ Schutzgemeinschaft Libellen in Baden-Württemberg e.V, Karlsruhe, Germany \\ ${ }^{8}$ Planung für alternative Umwelt GmbH, Gresenhorst, Germany \\ ${ }^{9}$ Landesanstalt für Umwelt Baden-Württemberg, Karlsruhe, Germany \\ ${ }^{10}$ Landesamt für Landwirtschaft, Umwelt und ländliche Räume Schleswig-Holstein, Flintbek, Germany \\ ${ }^{11}$ Naturschutzinstitut Freiberg, Freiberg, Germany \\ ${ }^{12}$ UK Centre for Ecology \& Hydrology, Wallingford, UK \\ ${ }^{13}$ Arbeitskreis Libellen Thüringen, Jena, Germany \\ ${ }^{14}$ Landesamt für Umweltschutz Sachsen-Anhalt, Halle (Saale), Germany \\ ${ }^{15}$ Arbeitskreis Libellen der DELATTINIA e.V. - Naturforschende Gesellschaft des Saarlandes, Tholey-Hasborn, Germany \\ ${ }^{16}$ WÖG Willigalla Ökologische Gutachten, Mainz, Germany \\ ${ }^{17}$ Institute of Biology/Geobotany and Botanical Garden, Martin Luther University Halle-Wittenberg, Halle, Germany \\ ${ }^{18}$ Faculty of Agricultural and Environmental Sciences, University of Rostock, Rostock, Germany
}

\section{Correspondence}

Diana E. Bowler, German Centre for Integrative Biodiversity Research (iDiv) Halle-Jena-Leipzig, Puschstraße, 04103 Leipzig, Germany.

Email: diana.e.bowler@gmail.com

Funding information

German Research Foundation, Grant/Award Number: DFG FZT 118 and 202548816

Editor: Markus Franzén

\begin{abstract}
Aim: Recent studies suggest insect declines in parts of Europe; however, the generality of these trends across different taxa and regions remains unclear. Standardized data are not available to assess large-scale, long-term changes for most insect groups but opportunistic citizen science data are widespread for some. Here, we took advantage of citizen science data to investigate distributional changes of Odonata. Location: Germany. Methods: We compiled over 1 million occurrence records from different regional databases. We used occupancy-detection models to account for imperfect detection and estimate annual distributions for each species during 1980-2016 within $5 \times 5 \mathrm{~km}$
\end{abstract}

This is an open access article under the terms of the Creative Commons Attribution License, which permits use, distribution and reproduction in any medium, provided the original work is properly cited.

(c) 2021 The Authors. Diversity and Distributions published by John Wiley \& Sons Ltd. 
quadrants. We also compiled data on species attributes that were hypothesized to affect species' sensitivity to different drivers and related them to the changes in species' distributions. We further developed a novel approach to cluster groups of species with similar patterns of distributional change to represent multispecies indicators. Results: More species increased (45\%) than decreased (29\%) or remained stable (26\%) in their distribution (i.e. number of occupied quadrants). Species showing increases were generally warm-adapted species and/or running water species, while species showing decreases were cold-adapted species using standing water habitats such as bogs. Time series clustering defined five main patterns of change-each associated with a specific combination of species attributes, and confirming the key roles of species' temperature and habitat preferences. Overall, our analysis predicted that mean quadrant-level species richness has increased over most of the time period.

Main conclusions: Trends in Odonata provide mixed news-improved water quality, coupled with positive impacts of climate change, could explain the positive trends of many species. At the same time, declining species point to conservation challenges associated with habitat loss and degradation. Our study demonstrates the great value of citizen science and the work of natural history societies for assessing large-scale distributional change.

\section{KEYWORDS}

biodiversity monitoring, citizen science, long-term change, occupancy-detection models, range-shifting, trait-based

\section{1 | INTRODUCTION}

Recent studies suggest long-term declines of insect populations in different parts of Europe (Conrad et al., 2006; Hallmann et al., 2017; Homburg et al., 2019; Valtonen et al., 2017). Such declines are a major conservation concern, especially because they could have a broad range of cascading effects for other species (Cardoso et al., 2020; Hallmann et al., 2014). However, many studies on insect change are based on local or small-scale datasets and their representativeness of large-scale patterns is unclear. Assessing change over large spatial scales is difficult for most insect taxa due to a lack of standardized monitoring. Nonetheless, effective conservation policies strongly rely on knowledge of the large-scale trends of species. To facilitate conservation decision-making, there is an urgent need to make use of all available data to estimate large-scale and long-term changes in insect populations and communities.

While large-scale standardized insect monitoring is rare, at least beyond butterflies (van Swaay et al., 2008), large amounts of opportunistic data, without a common sampling protocol, are collected by citizen science (CS; Chandler et al., 2017). Citizen science data are associated with numerous statistical challenges but they have the advantage of a large spatial coverage and a reasonable time span. Moreover, as some citizen scientists are active year-round, CS data also tend to capture a larger proportion of the biological community, including rare species, than standardized data (Bradter et al., 2018).
As CS data have become more accessible, there has been simultaneous development of methods to analyse such data (Isaac et al., 2014; Rapacciuolo et al., 2017; van Strien et al., ,2010, 2013). Occupancydetection models have emerged as one approach that is robust to different ways citizen scientists collect data, by explicitly modelling heterogeneity in survey effort and species detectability (Isaac et al., 2014).

Odonata are a good case study for the application of occupancydetection models to study long-term change because they are subject to extensive CS recording. Recent studies of dragonflies in different European countries suggest many species have increased in occurrence (Powney et al., 2015; Termaat et al., 2019). In general, there is evidence of recent population increases of many freshwater organisms in parts of Europe, thought to be due to better waste water treatment enabling recovery from previous impacts of water pollution (Van Klink et al., 2020; van Strien et al., 2016), especially following the implementation of the European Water Framework Directive (WFD) in the 2000s (Giger, 2009; Hering et al., 2010). Climate changes signals have also been apparent by the northward expansion of southern species (Hickling et al., 2006; Ott, 2010).

Many studies on biodiversity change have focused only on the simple long-term mean trend of a species but this approach can mask a diversity of more complex temporal responses (Baranov et al., 2020; Outhwaite et al., 2020). Moreover, simple models can produce trend estimates driven by fluctuations in particular years 
(Seibold et al., 2019). Recent analyses of invertebrate changes in the UK found both time periods of increases and time periods of decreases, which varied among taxa (Macgregor et al., 2019; Outhwaite et al., 2020). For instance, UK freshwater organisms decreased between 1970 and the mid-1990s but increased from then until 2010 (Outhwaite et al., 2020).

We used opportunistic data, including CS data, to study Odonata distributional change between 1980 and 2016 in Germany, which has the highest Odonata species richness in Europe (Brockhaus et al., 2015; Kalkman et al., 2018). We studied change in terms of the long-term trends but also the specific temporal patterns of change over time. To explore possible drivers of change, we identified species attributes (i.e. species-specific characteristics) associated with distributional changes. This analysis was in part exploratory, to identify predictive attributes, and in part hypothesis-driven, for some key attributes assumed to link to specific drivers. We hypothesized that sensitivity to climate change may be affected by species' temperature preferences, while sensitivity to environmental management would be affected by species' habitat preference. Specifically, we predicted increases of warm-adapted and early spring species and decreases of cold-adapted species, as well as increases of running water species, because these are thought to most benefit from climate change and improved water and environmental management (Termaat et al., 2015). We hypothesized to find the strongest recovery of running water species especially during the 2000s when the WFD activities began, but recovery may also be seen earlier due to improved wastewater treatment in the 1990s. By contrast, increases associated with climate change were expected to be already visible from the 1980s. Finally, we tested whether communities had become more dominated by widespread and generalist species in line with biotic homogenization (Powney et al., 2015).

\section{2 | METHODS}

\section{1 | Data compilation}

In collaboration with the Society of German speaking Odonatologists (GdO) and various conservation agencies representing different federal states, we compiled 1,198,708 occurrence records on Odonata across Germany. The aggregated dataset comprised heterogeneous data, collected by both official and voluntary nature conservation organizations, without a common sampling protocol; however, experienced naturalists collected most of the data (Brockhaus et al., 2015; Mauersberger et al., 2013; Petzold \& Fritzlar, 2014; Trockur, 2013). Available data usually included information on observer or project, date of observation, life stage of species and geographic coordinates or ordinance survey quadrant (Meßtischblatt Quadrant, MTBQ) of c. $5 \times 5 \mathrm{~km}$ (Goertzen \& Suhling, 2019). We supplemented our dataset with observations from iNaturalist-removing duplicates and filtering to "research grade" (i.e. have been verified as reliable) to ensure the highest data quality, but these comprise only a small part of the total database $(4.3 \%$ of the records, exclusion of these records does not affect our results).

\section{2 | Data processing}

We excluded: (a) data before 1980 because there were relatively few; (b) survey quadrants if they had not been visited in at least two separate years, so that they contain some information on change between years (Outhwaite et al., 2018), (c) observations of freshwater larvae because they must be sampled differently to adults and exuviae that are found on land (93\% of the observations were of adults) and (d) species seen in less than $25 \%$ of years (4 species: Coenagrion hylas, Gomphus simillimus, Lestes macrostigma, Onychogomphus uncatus) due to insufficient data to estimate a trend. We set the bar low for inclusion so that we could examine the trends of rare species, but later we examined the uncertainty of the model estimates. The least observed included species was Oxygastra curtisii, with 43 records over 11 years while the most observed species was Ischnura elegans with 88,486 records over all 37 years. However, most species were seen in almost all years (median $=37$, lower quartile $=36$ ). We included seasonal migratory species, such as Anax ephippiger and Sympetrum fonscolombii, even though they do not overwinter in Germany. Our trend estimation (described below) focuses on the trend among years during the main flight period of each species in Germany. Overall, 81 species of Odonata were included in the last published atlas for Germany (Boudot \& Kalkman, 2015; Brockhaus et al., 2015)-our analysis included 77 species after applying the above exclusion criteria (Table S1). Following these filtering steps, our dataset was reduced to 1,073,129 records (Figure 1).

\subsection{Species attribute data}

We selected species attributes for which there are available data and are known to show large differences among species. In particular, we were interested in attributes that might affect species' vulnerability to climate change and habitat/land-use change.

Distribution: We estimated species' European geographic range size as the number of occupied grids $(50 \times 50 \mathrm{~km})$ in a published atlas (Boudot \& Kalkman, 2015).

Species temperature preference: Species' temperature preferences were calculated by overlaying each species' European distribution with an average temperature map from E-OBS v. 19e (Cornes et al., 2018) following other studies (Jiguet et al., 2007). For each species, we calculated the mean of the mean daily temperatures of occupied grid cells. While we call this variable "temperature preference," its calculation did not aim to estimate species' optimal temperatures but rather to place species on a gradient from those preferring cooler temperature to those preferring warmer temperatures.

Life history: Data on voltinism, that is number of generations per year, were compiled from Corbet et al. (2006), complemented by expert knowledge within the co-author team. We applied a weighted mean of fuzzed-coded species affinities (values assigned to multiple categories reflecting the relative commonness of that category for the species, summing to 10 across all categories) to voltinism categories: multivoltine (coded as 5), bivoltinie (4), univoltine (3), semivoltine 
(a)

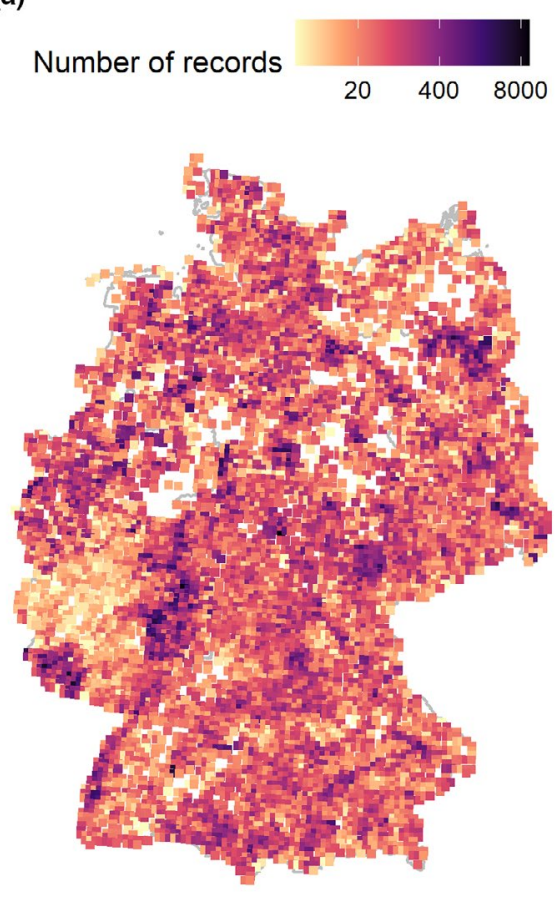

(b)

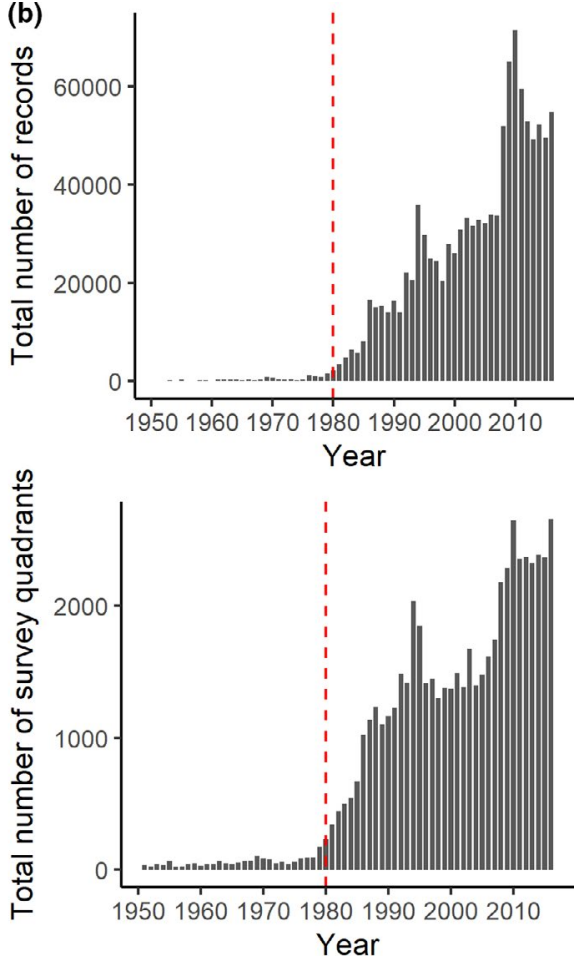

FIGURE 1 (a) Spatial distribution of Odonata occurrence records for each c. $5 \times 5 \mathrm{~km}$ survey quadrant in Germany. Shading refers to the number of occurrence records between 1980 and 2016 (subset to quadrats with records in at least 2 years). (b) Temporal distribution of the number of annual occurrence records (top) and annual number of visited survey quadrants (bottom). The red dashed vertical line denotes the start of our study period
(2) and partivoltine (1). This weighted mean ranged between 1 (for a fully partivoltine species) and 5 (for a fully multivoltine species).

Phenology: Mean start dates of the main flight period were taken from Boudot and Kalkman (2015), which provided start date at a resolution of monthly tertiles. Species' phenologies vary geographically but the data presented were usually for Bavaria, southern Germany. However, like for temperature preference, the aim was to create a variable that placed species on a gradient from those appearing early in the year to those appearing later.

Habitat: Main habitat preferences were classified according to descriptions in Dijkstra (2006) and Boudot and Kalkman (2015). Each species was coded to whether they use the following habitats: streams, rivers, ponds, lakes, ditches, canals, fenland, bogs, forest and quarries/pits.

Morphology: Hind wing length (median of lower and upper values) was taken from Dijkstra (2006).

Threat-level: We compiled data on the 2015 red list classification for each species in Germany (Ott et al., 2015). We aligned the German categories with the international IUCN categories following Jansen et al. (2020).

Species attribute data are provided in Dryad datafile 1.

\subsection{Annual occupancy estimates}

The finest unit of our analysis was a visit, referring to species observations collected on a given date in a given survey quadrant by a given observer/project (van Strien et al., 2010). Therefore, we organized the data into a list of species records seen on a given visit. Following others (Kéry et al., 2010), species' absences (non-detections) were inferred from observations of other species on a given visit. We used occupancy-detection models that account for imperfect detection to analyse the presence/absence (detection/non-detection) of species on a visit, which have been used in previous studies using opportunistic CS data (Outhwaite et al., 2020; van Strien et al., 2013) and tested in simulation studies (Isaac et al., 2014). By analysing the data at the level of a visit, the increase in the total annual number of records (Figure 1) does not bias the trend estimation (Isaac et al., 2014).

Non-detections occur when a species inhabits a site but is not detected by the observer during a visit. Detection probability here also includes recording probability (i.e. the citizen scientist does not necessarily record all species that they detect). Detection probability is estimated by making an assumption about closure: a period during which species' occupancy does not change. We assume closure during the flight period of each species within the same year. The number of times a species was/was not seen during this period of closure informs on detectability. Hence, repeated visits to the same survey quadrants within the same year are required to estimate detection probabilities. In our dataset, on average, $51 \%$ of survey quadrants were visited at least twice in a given year (range over years between $49 \%$ and $58 \%$ ). Moreover, revisited survey quadrants were on average visited 3 times within a year (range of mean over years between 2.3 and 3.9 times). We estimated the flight period of each species as between the lower $5 \%$ and upper $5 \%$ of days of year when each species was seen across all records. We only fit the model for each species to the subset of records during the flight period to meet the closure assumption. Models were fit to each species separately.

Letting $z_{i, t}$ refer to the true occupancy status for a species in a survey quadrat $i$ in a year $t$, we modelled occurrence probability $(\psi)$ 
as a function of site and year variation. Year variation was modelled by including year as a fixed effect factor. Site variation was modelled as a series of random terms: ecoregion variation (Bundesamt für Naturschutz, 2008) at two spatial scales (level 1:7 coarser-scale regions and level 2: finer-scale 487 regions) and survey quadrant variation. While we were only interested in the mean yearly variation in occupancy, we included these spatial terms to account for the known large amount of spatial variation in species' occurrences across Germany. Hence, our occurrence model was:

$$
z_{i, t} \sim \operatorname{Bernoulli}\left(\psi_{i, t}\right)
$$

$\operatorname{logit}\left(\psi_{i, t}\right)=$ Year $_{t}+$ Ecoregion_1 $_{i}+$ Ecoregion_$_{-}+$Quadrant $_{i}$

Detection probability $(p)$ was modelled for each visit $j$ to a given quadrant in a given year and assumed to depend on year and day of year (yday, accounting for species' phenology). Following Outhwaite et al. (2019), survey effort was modelled as a function of list length, that is number of species reported on a visit (a categorical variable with three levels: a single list ( 1 species, $31 \%$ visits), a short list (2-3 species, $24 \%$ visits) or a longer list (4 or more species, $45 \%$ visits, set as the reference level).

$\operatorname{logit}\left(p_{i, t, j}\right)=\alpha_{t}+\beta_{y d} y_{\text {day }}+\beta_{y d 2} y_{\text {day }_{j}^{2}}^{2}+\beta_{\text {sil }}$ single_list $_{j}+\beta_{\text {shl }}$ short_list $_{j}$

The observed detection data for a given species, y $(0$ or 1 , for non-detection or detection), on each visit are then assumed to be drawn from a Bernoulli distribution conditional on the presence of the species in that quadrant and year:

$$
y_{i, t, j} \mid z_{i, t} \sim \operatorname{Bernoulli}\left(z_{i, t} \cdot p_{i, t, j}\right)
$$

Using the estimated occurrences $\left(z_{i, t}\right)$, we calculated a number of derived parameters: (a) the proportion of survey quadrants that were occupied by a species in each year (hereafter "occupancy proportion"); (b) the slope of a regression line through the annual occupancy proportions for each species (hereafter "trend"); and (c) ratio of occupancy proportion between the first and last year (Available in Dryad datafiles 1 and 2). These statistics were calculated during model fitting, and hence, the uncertainty in occupancy estimates was retained in each parameter.

The models were fit by Bayesian inference using JAGS, a program for fitting hierarchical models using Markov chain Monte Carlo simulation. We used vague priors for most parameters but a random walk prior, to share information across years, for the year fixed effect on occupancy (Outhwaite et al., 2018). We used 3 chains with 30,000 iterations, discarding the first 15,000 as burn-in. Model convergence was assessed by the Rhat statistic and traceplots. A small fraction of the annual predictions did not meet the standard threshold of $<1.1$ for Rhat (1.6\% of annual occupancy estimates) but these Rhats were still reasonably close (all $<1.26$ ) and their exclusion had little effect on our overall results (see "Long-term trends"). Moreover, we carried our posterior predictive checks by calculating a Bayesian p-value. This was calculated as a Pearson chi-square statistic between the observed total number of species' detections in each year and the predicted number generated by simulating values from the fitted model. Bayesian $p$-values close to 0 or 1 would indicate poor model fit (Kéry \& Royle, 2015). Our values were on average 0.46 across species (interquartile range $=0.43,0.50$ ). Predicted time series plots were also examined by Odonata experts in Germany to check for plausibility. The model code is provided in the Supporting information.

We ran a series of sensitivity analyses to check whether our results were robust to some modelling decisions. First, we ran dynamic-occupancy models that explicitly model changes in occupancy between years as either caused by persistence probability when the site was occupied in the previous year or by colonization probability when the site was not occupied in the previous year (Kéry et al., 2013). For most species, these models produced similar patterns to the simpler occupancy model above, but for the rarer species, the parameters of the dynamic-occupancy model showed lower convergence and large uncertainty, especially for the earlier years when there were less data. Hence, we used our simpler occupancy model that produced satisfactory results for all species. Second, we explored a more complex detection model in which the effect of day of year (linear and quadratic effects) was allowed to vary among years, to allow for possible changes in phenology, for example due to climate change. The species trend estimates of this model were highly correlated with the estimates from the simpler model $(r=.99)$; hence, we proceeded with the simpler model. Last, we re-ran our original analysis with data limited to the set of quadrants that were surveyed at least once in each decade of our study period (e.g. at least once in the $80 \mathrm{~s}, 90 \mathrm{~s}$, 00 s and 10s), hence controlling for any effects of variation in site selection over time. This analysis used data from $13 \%$ of the original survey quadrants and again the estimated trends were highly correlated with those estimated using the full dataset $(r=.97)$ but with larger uncertainties.

\section{5 | Long-term trends}

We analysed the interspecific variation in distribution trends using a linear regression model, with species attributes as explanatory variables and species' trend estimates as the response. Correlations among species' attributes were examined to check for any possible collinearity issues (all $|r|<.6$ ). We first conducted an exploratory analysis with each of the habitat variables in simple regression models. Using these models, we identified habitat variables that explained variation in trends (i.e. if $p<.05$ ). We then combined the selected habitat variables along with the other variables (temperature preference, voltinism, flight start date and wing length) in a multiple regression model of long-term trends. We performed step-wise deletion, removing insignificant attributes, to identify the best model. We also used a linear model to compare the trends of species with different red list status. We re-ran our trait analyses excluding the 
species with a low number of detection records (Anax ephippiger, Boyeria irene and Oxygastra curtisii) and for which the Rhat values indicated the weakest convergence of annual occupancy and trend estimates, but the results did not change.

As species do not necessarily provide independent data points due to shared evolutionary histories, we checked whether the results of the regression were consistent after accounting for species relatedness. We used the taxonomic classification to build a simple phylogenetic tree with equal branch lengths for each taxonomic rank (Paradis \& Schliep, 2019). We then included the tree as a correlation structure (corPagel-based on Brownian motion) in a generalized least-squares model (Paradis \& Schliep, 2019). As this had little effect on the effect sizes of the attributes, and the estimated phylogenetic signal was close to zero (likelihood ratio test between models with and without the correlation structure, $p=.36$ ), we present the simpler model without this correlation structure.

\section{6 | Temporal patterns}

We used a time series clustering method to group together species showing similar dynamics. While each species has a unique time series pattern, this approach aims to simplify the complex reality and identify the most dominant patterns of change. We used the Pearson correlation coefficient as a dissimilarity measure of species annual occupancy proportions using the TSclust package (Montero $\&$ Vilar, 2014) and clusters were split using partitional clustering. The estimates of annual occupancy proportions were preprocessed via logit transformation. We selected the number of clusters using several cluster indices (average silhouette width, Dunn index, separation index), assessed over the range of 2-20 clusters. We visualized the temporal change in each pattern by calculating the annual geometric mean of the occupancy proportions for the set of species in each cluster (Buckland et al., 2011). To include the uncertainty of species' occupancies, we combined 1,000 random draws from the posterior of the annual occupancy estimates for the species in each cluster and calculated the upper and lower $2.5 \%$ quantiles of the geometric means to provide $95 \%$ confidence intervals. We further examined the sensitivity of our inferences to our clustering decisions by (a) checking the influence of species with large distribution changes and consistently rare species and (b) checking the effect of cluster number by one fewer and one more possible cluster (see Figure S4).

\section{7 | Assemblage-level properties}

To examine the implications of the species-level changes for the total Odonata species pool (referred to here as assemblage-level), we aggregated the predicted occupancy proportions of all species. We calculated for each year: mean species richness and diversity (Shannon index) using all species' occupancy proportions and community-weighted means for range size (mean range size of each species weighted by its occupancy proportion). We retained the uncertainty of the species' estimates by repeating the calculations for 1,000 random draws from the posterior distributions of the species' occupancies and calculating the upper and lower $2.5 \%$ quantiles.

We used $\mathrm{R}$ version 3.6.3 for all analysis. Statistical significance was assessed when $95 \%$ confidence intervals did not overlap zero.

\section{3 | RESULTS}

\section{1 | Long-term trends}

Of the 77 species, we found that 35 were significantly increasing in their distribution (i.e. number of occupied quadrants) and 22 were significantly decreasing in their distribution (Figure 2a). Of the 20 species with a non-significant trend, all had a small trend estimate (within 5\% long-term change). The median trend (i.e. annual change in proportion of occupied sites) for increasing species was 0.0037 (interquartile range $=0.0014,0.0064$ ), while the median trend for decreasing species was $-0.0038(-0.0060,-0.0016)$. Crocothemis erythraea and Coenagrion scitulum had the largest distributional increase (increase by a factor of 53 and 23, respectively, in number of occupied grid cells), while Sympetrum flaveolum and Coenagrion lunulatum had the largest distributional decrease (decrease by a factor of 0.01 and 0.13 , Figure $2 b$ ) between 1980 and 2016. The proportions of dragonflies versus damselflies increasing (24/50 versus $11 / 27)$ and decreasing (11/50 versus $11 / 27)$ were not significantly different (chisq test, $p>$.1). Estimated distribution trends were consistent with the current red list status for Germany. Threatened species (vulnerable, endangered, critically endangered) had more negative population trends compared with species of least concern or near threatened ( $p<.05$, Figure $2 c$ ). Mean species detection probability was 0.25 (interquartile range across species $=0.20,0.31$ ) (Figure S2).

In a multiple regression model, the most important attributes explaining variation in species' long-term trends were temperature preference, flight start date, wing length and river use (Figure 3). Temperature preference was positively associated with species' trends: warm-adapted species increased while cool-adapted species decreased (Figure 4). Species that appear as flying adults earlier in the year and those with longer wings (in absolute terms) also had more positive trends. In the analysis of habitat associations, species occupying river habitats tended to increase, while species associated with bog habitats tended to decrease (Figure 4). While bog use was negatively associated with species' trends in the simple regression model, it was no longer significant in the multiple regression model (Figure 3). This was probably because bog species were associated with colder temperature preferences $(r=-.54)$, leading to a more uncertain effect of bog use after accounting for temperature preference. Voltinism had little importance (Figures 3 and 4). Together, temperature preference, wing length, flight start date and river use explained $27 \%$ of the variation in trends among species. 
FIGURE 2 Estimated nationwide trends in Odonata species' distributions. (a) long-term trends ( $y$-axis, interpreted as mean annual change in \% occupied sites, $0=$ no change) for each species ( $x$-axis), ordered by their magnitude of trend; (b) ratio in the estimated number of occupied quadrants between the last (2016) and first (1980) year ( $y$-axis, 1 = no change, 2 =doubling) for each species ( $x$-axes), ordered by their magnitude of change, and (c) boxplots (outliers are shown as solid points) of the association between long-term trend and red list classification (number of species in each group is shown in brackets). See Figure S1 for time series of individual species and Dryad datafile 1 for data on the trends of each species (a) Trend significant decrease insignificant significant increase

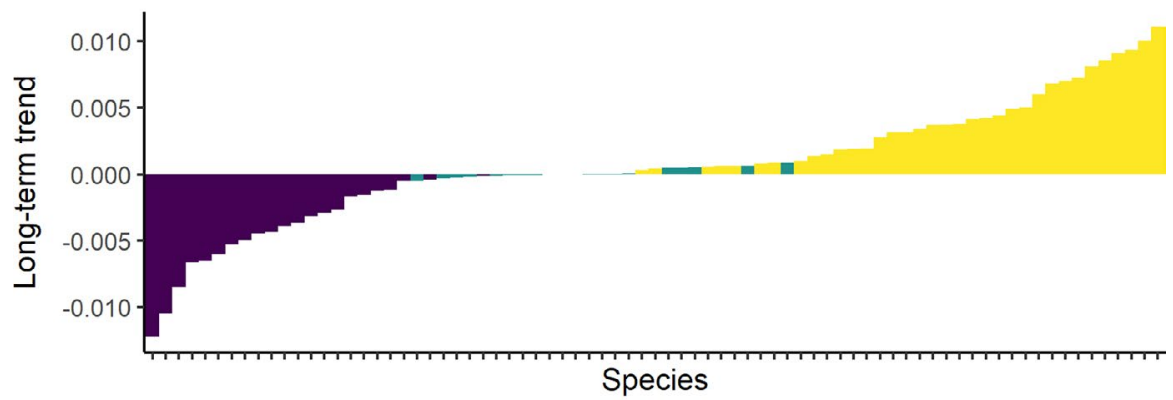

(b)
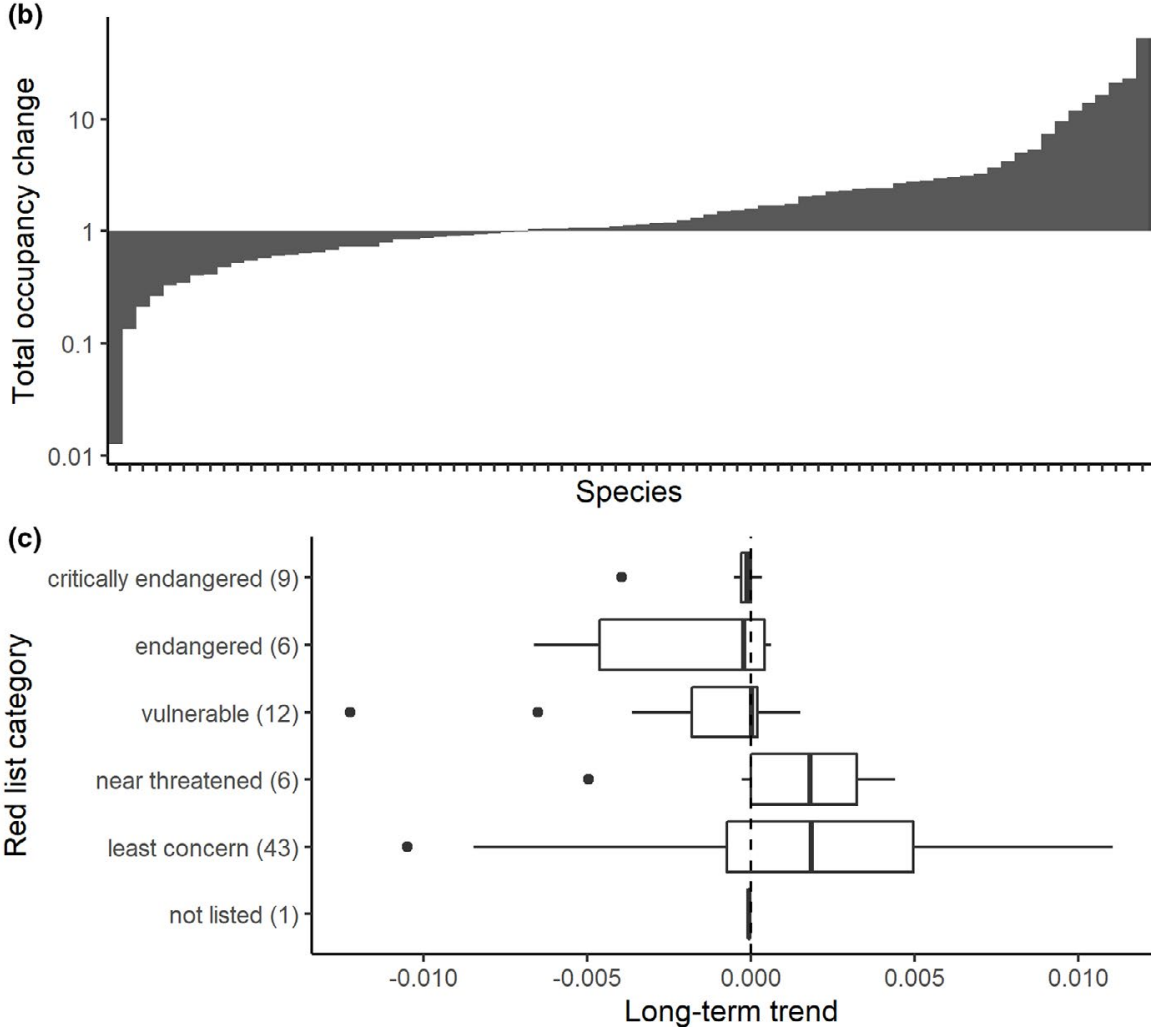

\subsection{Analysis of temporal patterns}

Time series clustering of species' occupancy dynamics resulted in five main grouping of species with similar patterns of change (Figure 5). Cluster classification explained $59 \%$ of the interspecific variation in long-term trends. Cluster 1, the largest group of 35 species, comprised species with a persistent increase in occupancy until the last years (Figure 5 a, median correlation of species annual indices $=.72$ [interquartile range, 0.54, 0.86]). Warm-adapted riverine species were most likely to be within this first group (Figure 5b). Cluster 2 included 10 species that initially decreased but increased since the 2000 s (Figure 5, median correlation $=.39[0.25,0.72]$ ). Cluster 3 included 9 species, mostly using bog habitats, which showed variable trends but were typically declining 2000s onwards (median correlation $=.52$ $[0.30,0.59])$. Cluster 4 included 12 species that were declining, especially in the last decade, and tended to be cold-adapted bog species (Figure 5 , median correlation $=.67[0.56,0.80]$ ). Finally, cluster 5 comprises 11 species with a strong decline in the 1980s and tended to be cold-adapted, small species (Figure 5, median correlation $=.86[0.72$, 0.92]). Sensitivity analysis defining one fewer cluster showed that clusters 4 and 5 might be grouped together as a declining species group (Figure S4B). While defining one additional cluster suggested a group of seven species that primarily increased in the 1980s (Figure S4C).

\section{3 | Assemblage-level consequences}

Predicted mean species richness per quadrat generally increased over the time period; however, some periods of decline were apparent during the 1980s and during the 2010s (Figure 6). Diversity shows similar trends, with increases until 2010 and decreases since then. Species that were grouped in the largest cluster, cluster 1 , most likely explain the overall species richness pattern. Time series of the weighted mean in range size suggested no simple shift towards widespread species - larger-range species became more dominant in the 1980s while smaller-range species became more dominant in the 1990s and 2000s. 


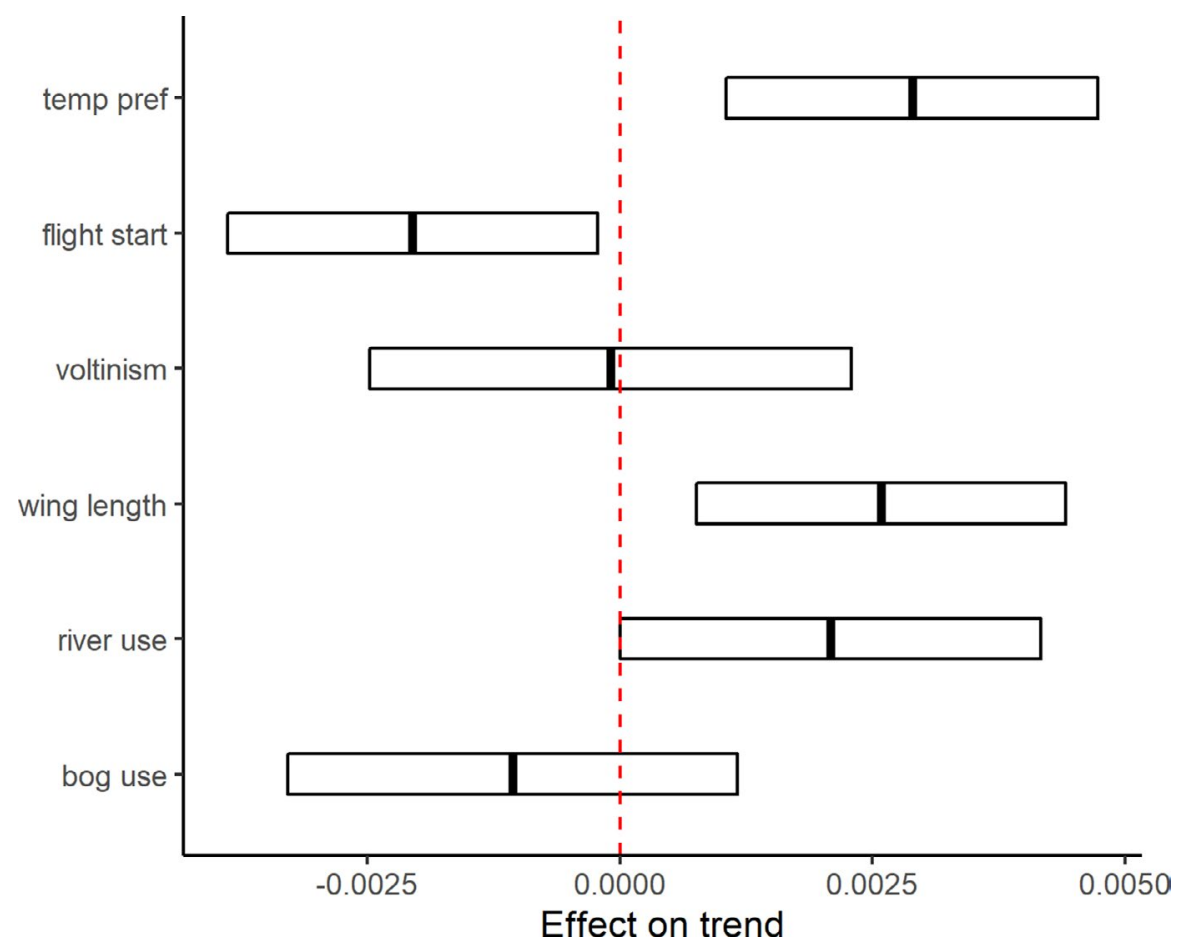

FIGURE 3 Effect of species' attributes on their long-term distribution trends tested in a multiple regression model. Continuous variables (all except river and bog use) were scaled to units of 2 standard deviations to facilitate comparison with the binary habitat variables. The dashed red line is the line of no effect. Shown are the mean effect $\pm 95 \%$ confidence interval. Table S2 provides the plotted values

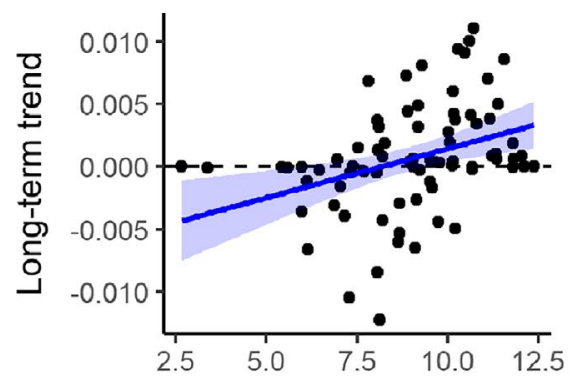

Temperature preference ${ }^{\circ} \mathrm{C}$
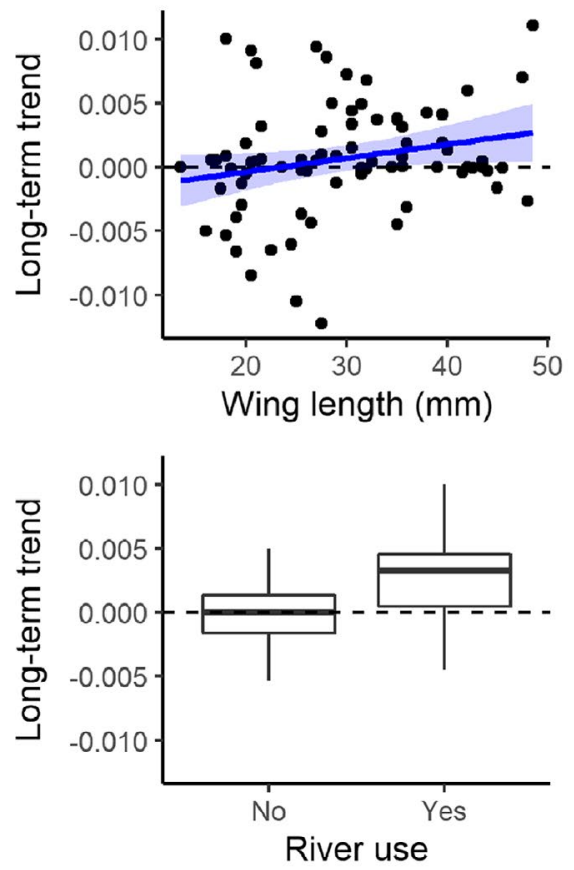

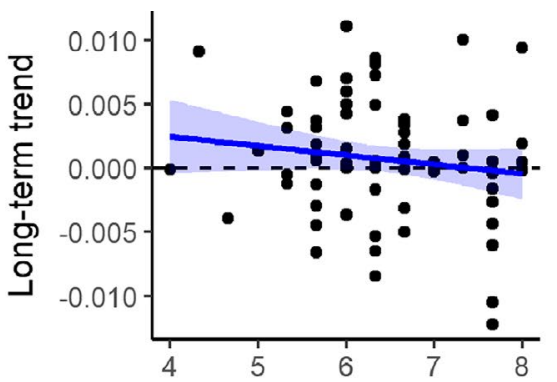

Start of flight period (month)
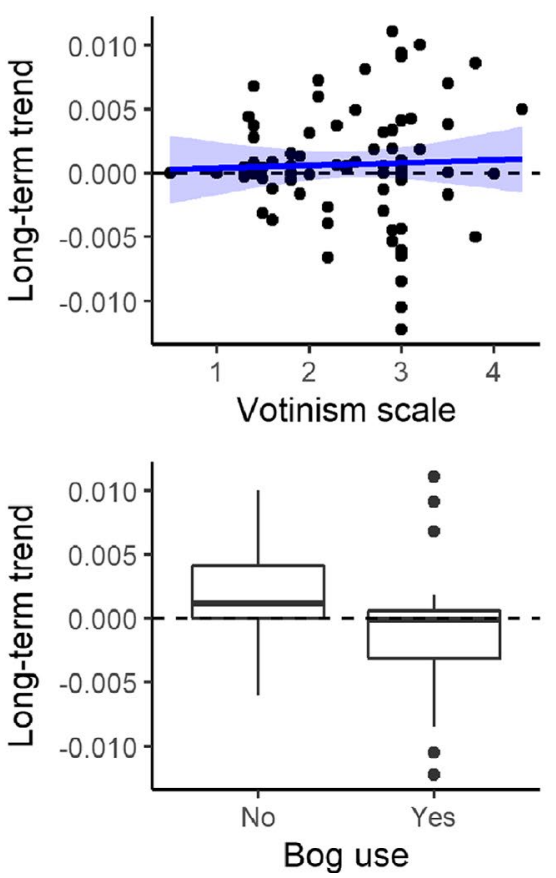

FIGURE 4 Relationships between each attribute and species' distribution trends, each point is a species. The blue line is a fitted simple regression line. Boxplots are shown for river and bog use. The dashed horizontal line is the line of stable trends. Statistical significance at the $5 \%$ level is inferred when the $95 \%$ confidence intervals for the effects do not overlap zero-these are shown in Figure 3. The effects were significant for temperature preference, flight state date, wing length and river use (marginally) 
(a)
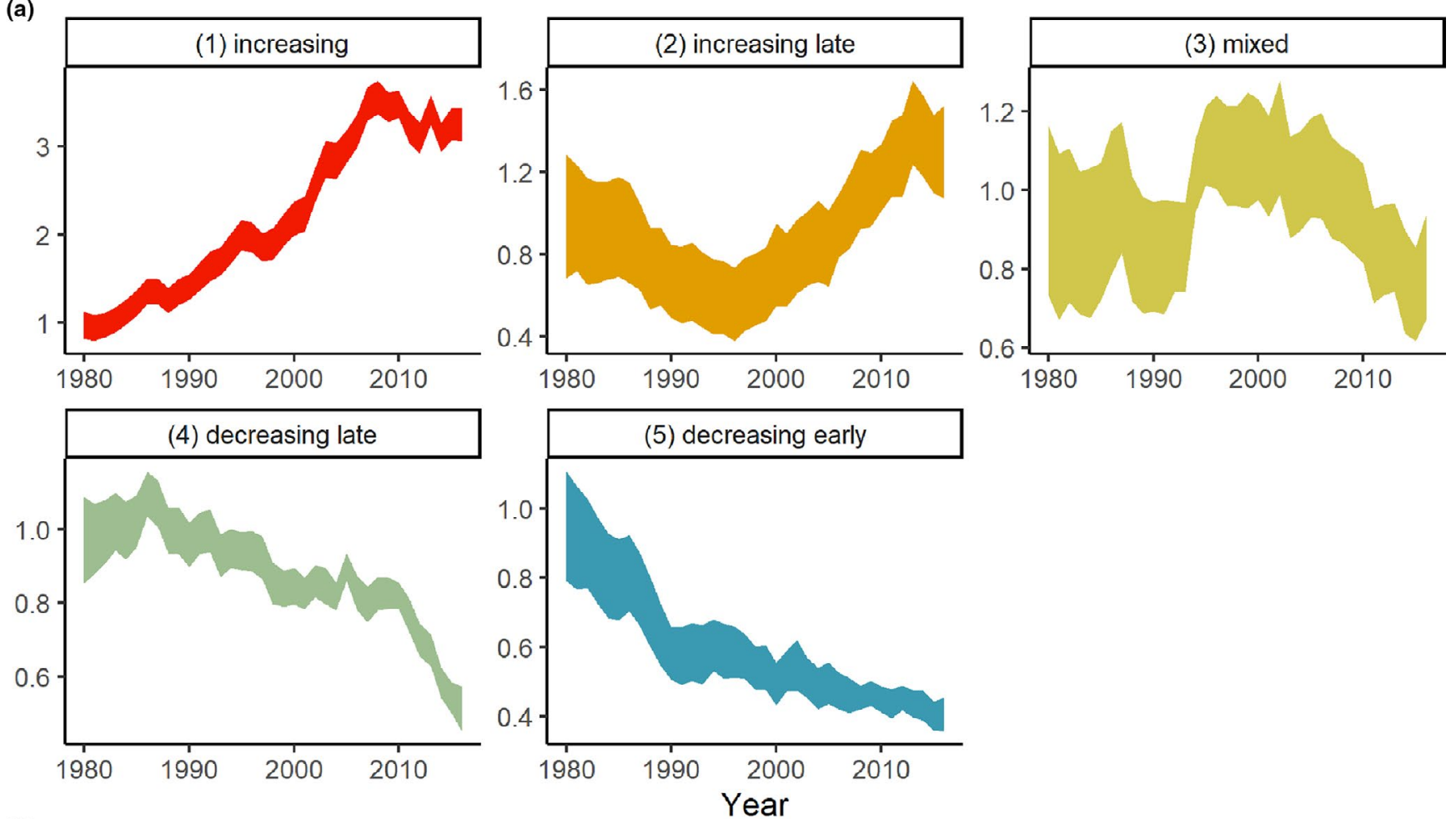

(b)
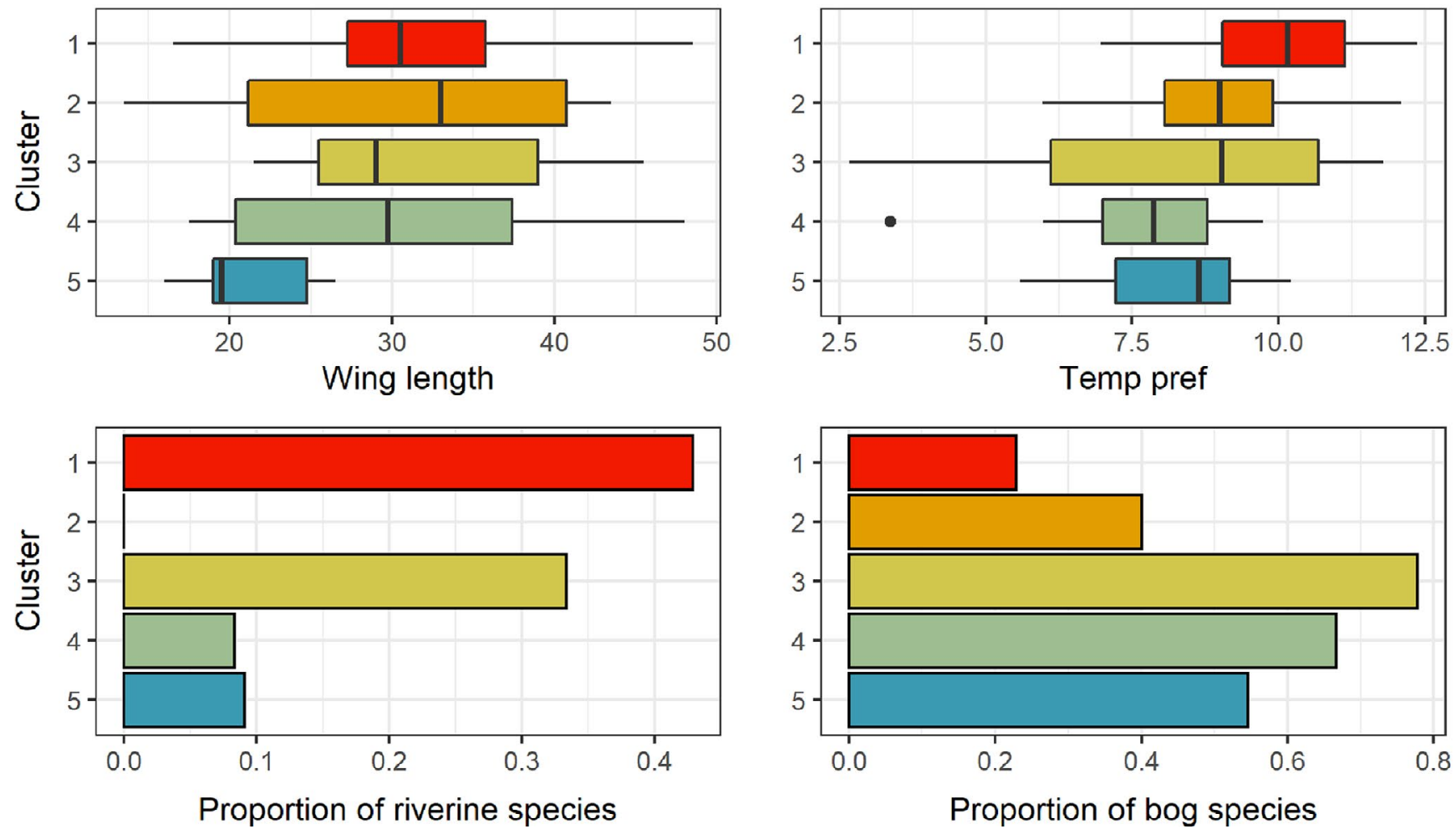

FIGURE 5 Time series clusters and associated attributes. (a) Each cluster reflects a common pattern of change in occupancy over time for a group of species. The index represents the annual mean occupancy estimate relative to 1980 . The number of species in each cluster was as follows: 35, 10, 9, 12 and 11. (b) The plots below shown boxplots or barcharts for attribute values within each cluster. See Table S3 for list of species in each cluster and Figure $\mathrm{S} 3$ for the species time series grouped by cluster. (a) was repeated by removing species with the most extreme occupancy changes in each cluster to check they were not driving the mean patterns-but similar patterns were found (Figure S4) 

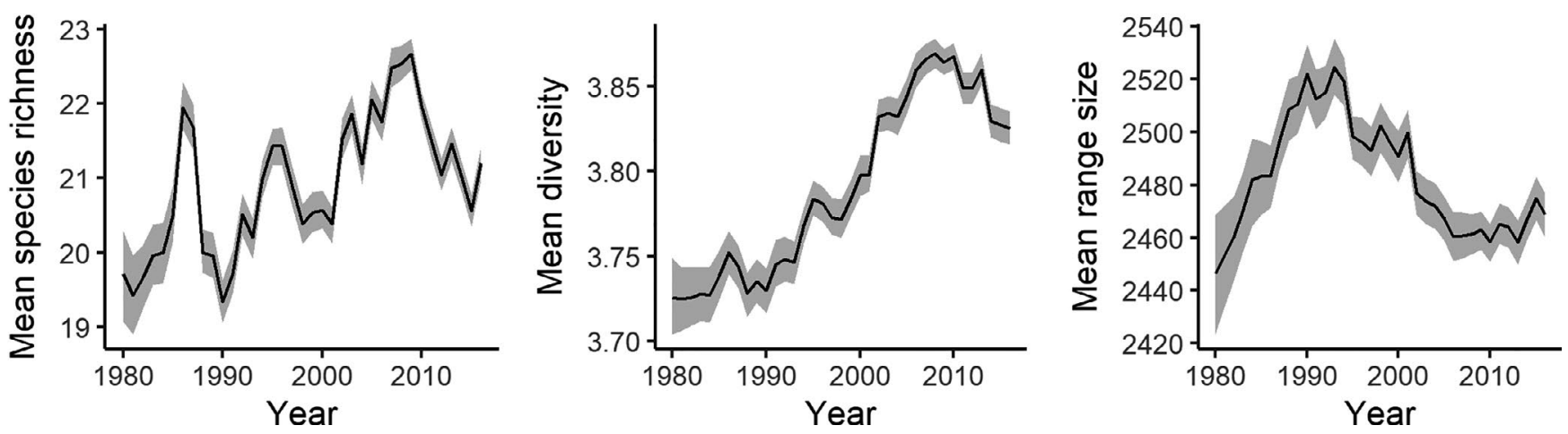

FIGURE 6 Time series of aggregate predictions across all species: mean species richness and diversity per survey quadrat, and weighted mean of European range size. Shown are means and $95 \% \mathrm{Cl}$ of the mean

\section{4 | DISCUSSION}

Freshwater habitats have faced multiple anthropogenic threats, including eutrophication, acidification, climate change and canalization (Vörösmarty et al., 2010). Globally, freshwater vertebrate species are reported to be declining (He et al., 2019). Hence, our findings of many stable or increasing Odonata species since 1980 in Germany might seem surprising. However, our results are consistent with other studies on Odonata species that show increasing trends in Europe (Powney et al., 2015; Termaat et al., 2019; van Strien et al., 2016) and more generally positive trends in biomass of freshwater insects found in some datasets (Van Klink et al., 2020). Hence, our results suggest a more complex range of species' distribution changes than the current simplistic narrative of declining insect populations. Additionally, our findings highlight the value of opportunistic data, especially from CS, in combination with statistical tools, for assessing large-scale biodiversity change.

Climate change probably plays a key role in the success of many Odonata species in Europe. As highly mobile organisms, many Odonata species may have adaptive capacity to respond to climate change, demonstrated by range-shifts reported in other countries (Flenner \& Sahlen, 2008; Hickling et al., 2005) and may be responding stronger to climate change than many other terrestrial species (Hassall, 2015). We find that formerly rare warm-adapted species such as Crocothemis erythraea and Erythromma viridulum have undergone large range expansions across Germany. Increases in the occurrence of species typically appearing earlier in the year might also be linked to warming temperature. Earlier and longer reproduction seasons may increase the potential for more than one generation within a year (Braune et al., 2008) or allow early breeders to monopolize resources ahead of later-breeding species (Suhling \& Suhling, 2013). Additionally, we found that wing length was an important predictor. One of the biggest winners has been the Emperor, Anax imperator, a strong flier with long wings (Rüppell, 1989).

Our findings may also reveal the impacts of improved environmental management, especially for rivers. Many running water species were increasing 1980 onwards even though the EU Water Framework Directive (WFD), which aimed to improve water quality, was not adopted until 2000 (Hering et al., 2010). This is probably because there was a range of other conservation and environmental management projects to improve water quality prior to 2000 in Germany (Detering, 2000; Giger, 2009). These projects included expansion of water purification plants; improved watercourse management (less removal of vegetation and disturbance of sediments); Fauna-Flora-Habitat Directive activities that targeted specific species and conservation measures to improve degraded wetlands. Positive trends of dragonflies in the Netherlands were also thought to partly reflect habitat improvements (Termaat et al., 2015). River restoration projects in Europe have also allowed some recovery of other taxa, such as fish, though not necessarily to former historic states (Thomas et al., 2015). The success of riverine species may also reflect some synergism in the impacts of climate change and environmental management, because improvements in water quality may have facilitated climate change-driven range expansion by increasing the establishment success of immigrants (Braune et al., 2008).

Despite improvements in some freshwater habitats, we also identified a significant number of declining, "loser" species. Decreases of cold-adapted species could represent range contraction due to physiological stress under warming climates; however, more likely, they are a consequence of habitat loss, associated with climate change and land-use. Some declining species, such as Sympetrum danae and Coenagrion hastulatum, are cold-adapted and typical of bog or moorland habitats, which are among the most threatened habitats in Europe (European Environment Agency, 2015). Overall, species of standing water habitats had more negative trends than those of running water habitats. While some types of standing water habitats, such as gravel quarries/sand pits, might have become more common, decreases in groundwater level due to overexploitation of water resources have probably reduced the availability of many small standing water bodies. Small or shallow water bodies have been also vulnerable to droughts (Opitz et al., 2019). The success of ongoing conservation projects to restore bogs and other standing water habitats requires ongoing monitoring (Dolny et al., 2018; Krieger et al., 2019).

Using time series clustering, we defined five characteristic patterns of distributional change that were common across multiple 
species. This approach separated species that differed in paths of change, even when their long-term mean trend was similar. While a simplification of reality, this approach aims to identify the dominant patterns of change. There are other approaches to visualize the time series patterns for specific groups of species, often called multispecies indicators (e.g. the Farmland Bird Index), but species are preassigned to groups with current methods and the resulting indicators can be sensitive to grouping decisions (Gregory et al., 2019). Here, we show how it is possible to allow species to naturally group based on the similarity of their dynamics using time series clustering, which has the potential to reveal the role of previously overlooked community changes and may be less prone to subjective species selection decisions. Moreover, further investigation of the timings of change may help shed more light on the relative importance of different drivers. Dennis et al. (2019) tested an alternative approach to multispecies indicators using functional data analysis. These approaches may be used to develop alternative sets of multispecies indicators that represent the multi-facetted nature of change within communities.

Despite evidence of species turnover, we found no trend towards biotic homogenization nor overall loss of diversity. Nonetheless, our findings have various implications for freshwater conservation in Germany. The strong associations between species attributes and distribution trends support the use of trait-based vulnerability assessments for conservation decision-making (Conti et al., 2014). However, increasing occurrences for some species represent expansion into new regions; while for other species, increases rather reflect recovery to formerly occupied parts of the range. The former group may be regarded as "neonatives" (Essl et al., 2019) and contribute to the development of novel species interactions and assemblages (Carrasco et al., 2018), with currently unclear repercussions for established/native species (Flenner \& Sahlen, 2008; Suhling \& Suhling, 2013). Decreasing distributions of other species have led to a decline in mean species richness during the 2010s. Standstills in the recovery of Odonata have been reported in the Netherlands (van Grunsven et al., 2020) and in the UK (Outhwaite et al., 2020). Ongoing monitoring and synthesis of habitat assessments are needed to assess the likely cause.

\section{1 | Data limitations}

As our analysis is based on opportunistic data, concerns should always remain about the robustness of the trends. During our study period, there was a large increase in the reporting of species' observations. Simulation tests of occupancy models have shown them to be robust to different scenarios of survey effort change over time because analysis is performed on observations at the visit level (i.e. detections from the same date and site; Isaac et al., 2014); however, we cannot rule out that different changes in data collection across time and space affected some of our results. Also, our analysis only focused on changes in distributions and not changes in abundance. For some species, increases or decreases in abundance may not yet have translated into changes in occupancy. We also only examined changes from 1980 onwards-most likely more historical data would highlight the earlier negative impacts of past water pollution and enable assessment of how much species have been able to recover to their former historical ranges (Goertzen \& Suhling, 2019; Outhwaite et al., 2020).

\section{5 | CONCLUSIONS}

Using an extensive citizen science dataset, our analysis revealed a complex picture of positive and negative, linear and nonlinear distribution changes of Odonata species in Germany over the past 35 years. Climate change, habitat change and environmental management have probably all played a role. Cold-adapted habitat specialists of standing water habitats are likely to be most vulnerable to further environmental change, while increases of species associated with river habitats signal the conservation success that can be achieved by better environmental management. Overall, our study demonstrates the value of the intensive recording efforts of citizen scientists in the past, often promoted and coordinated by natural history societies, and highlights the need to support these efforts in the future, especially given signs of ongoing Odonata declines over the last decade.

\section{DATA AVAILABILTY STATEMENT}

Species' annual occupancy estimates, trait data and distribution trend estimates are available in Dryad datafiles (https://doi. org/10.5061/dryad.73n5tb2wp).

\section{ACKNOWLEDGEMENTS}

This analysis was made possible through the efforts of many volunteer recorders over the past decades to whom we are very grateful. We thank especially the GdO-Gesellschaft deutschsprachiger Odonatologen e.V. We thank the various Arbeitskreise Libellen (Odonata working groups) across Germany, and Michael Frank, Holger Lueg, Rüdiger Mauersberger, Frank Fritzlar and Samuel Rauhut, and the Thüringer Landesamt für Umwelt, Bergbau und Naturschutz for sharing Odonata data for our project. We also thank Charlie Outhwaite and Bob O'Hara for their discussion at the sMon workshop. We much appreciate the support of the German Research Foundation (DFG) for funding the sMon working group (Trend analysis of biodiversity data in Germany) through the iDiv (DFG FZT 118, 202548816). NI is supported by the UK Natural Environment Research Council award number NE/ R016429/1 as part of the UK-SCAPE programme delivering National Capability. Open Access funding enabled and organized by Projekt DEAL.

\section{PEER REVIEW}

The peer review history for this article is available at https://publo ns.com/publon/10.1111/ddi.13274. 


\section{ORCID}

Diana E. Bowler (iD https://orcid.org/0000-0002-7775-1668

David Eichenberg (iD https://orcid.org/0000-0001-5740-5621

Frank Suhling iD https://orcid.org/0000-0003-2922-0261

Nick J.B. Isaac (iD https://orcid.org/0000-0002-4869-8052

Helge Bruelheide (iD https://orcid.org/0000-0003-3135-0356

Florian Jansen (iD https://orcid.org/0000-0002-0331-5185

Aletta Bonn (iD https://orcid.org/0000-0002-8345-4600

\section{REFERENCES}

Baranov, V., Jourdan, J., Pilotto, F., Wagner, R., \& Haase, P. (2020). Complex and nonlinear climate-driven changes in freshwater insect communities over 42 years. Conservation Biology, 34(5), 1241-1251. https://doi.org/10.1111/cobi.13477

Boudot, J. P., \& Kalkman, V. J. (Eds.) (2015). Atlas of the European dragonflies and damselflies. KNNC Publishing.

Bradter, U., Mair, L., Jonsson, M., Knape, J., Singer, A., \& Snall, T. (2018). Can opportunistically collected Citizen Science data fill a data gap for habitat suitability models of less common species? Methods in Ecology and Evolution, 9(7), 1667-1678. https://doi. org/10.1111/2041-210x.13012

Braune, E., Richter, O., Sondgerath, D., \& Suhling, F. (2008). Voltinism flexibility of a riverine dragonfly along thermal gradients. Global Change Biology, 14(3), 470-482. https://doi. org/10.1111/j.1365-2486.2007.01525.x

Brockhaus, T., Roland, H.-J., Bennke, T., Conze, K.-J., Günther, A., Leipelt, K. G., Lohr, M., Martens, A., Mauersberger, R., Ott, J., Suhling, F., Weihrauch, F., \& Willigalla, C. (2015). Atlas der Libellen Deutschlands. Libellula, Suppl. 14, 464.

Buckland, S. T., Studeny, A. C., Magurran, A. E., Illian, J. B., \& Newson, S E. (2011). The geometric mean of relative abundance indices: A biodiversity measure with a difference. Ecosphere, 2(9), art100. https:// doi.org/10.1890/es11-00186.1

Bundesamt für Naturschutz (2008). Daten zur Natur 2008. Landwirtschaftsverlag.

Cardoso, P., Barton, P. S., Birkhofer, K., Chichorro, F., Deacon, C., Fartmann, T., Fukushima, C. S., Gaigher, R., Habel, J. C., Hallmann, C. A., Hill, M. J., Hochkirch, A., Kwak, M. L., Mammola, S., Ari Noriega, J., Orfinger, A. B., Pedraza, F., Pryke, J. S., Roque, F. O., ... Samways, M. J. (2020). Scientists' warning to humanity on insect extinctions. Biological Conservation, 242, 108426. https://doi.org/10.1016/j. biocon. 2020.108426

Carrasco, D., Desurmont, G. A., Laplanche, D., Proffit, M., Gols, R., Becher, P. G., Larsson, M. C., Turlings, T. C. J., \& Anderson, P. (2018). With or without you: Effects of the concurrent range expansion of an herbivore and its natural enemy on native species interactions. Global Change Biology, 24(2), 631-643. https://doi. org/10.1111/gcb.13836

Chandler, M., See, L., Copas, K., Bonde, A. M. Z., López, B. C., Danielsen, F., Legind, J. K., Masinde, S., Miller-Rushing, A. J., Newman, G. Rosemartin, A., \& Turak, E. (2017). Contribution of citizen science towards international biodiversity monitoring. Biological Conservation, 213, 280-294. https://doi.org/10.1016/j.biocon.2016.09.004

Conrad, K. F., Warren, M. S., Fox, R., Parsons, M. S., \& Woiwod, I. P. (2006). Rapid declines of common, widespread British moths provide evidence of an insect biodiversity crisis. Biological Conservation, 132(3), 279-291. https://doi.org/10.1016/j.biocon.2006.04.020

Conti, L., Schmidt-Kloiber, A., Grenouillet, G., \& Graf, W. (2014). A traitbased approach to assess the vulnerability of European aquatic insects to climate change. Hydrobiologia, 721(1), 297-315. https://doi. org/10.1007/s10750-013-1690-7

Corbet, P. S., Suhling, F., \& Söndgerath, D. (2006). Voltinism in Odonata: A review. International Journal of Odonatology, 9, 1-44.
Cornes, R., van der Schrier, G., van den Besselaar, E. J. M., \& Jones, P. D. (2018). An Ensemble Version of the E-OBS temperature and precipitation datasets. Journal of Geophysical Research Atmospheres, 123(17), 9391-9409. https://doi.org/10.1029/2017JD028200

Dennis, E. B., Morgan, B. J. T., Fox, R., Roy, D. B., \& Brereton, T. M. (2019). Functional data analysis of multi-species abundance and occupancy data sets. Ecological Indicators, 104, 156-165. https://doi. org/10.1016/j.ecolind.2019.04.070

Detering, U. (2000). Das Gewässerauenprogramm NRW am Beispiel der oberen Lippe. In Bundesamt für Naturschutz (Ed.), Renaturierung von Bächen, Flüssen und Strömen, Angewandte Landschaftsökolgie (pp. S 153-162). Heft Nr. 37, Landwirtschaftsverlag Münster.

Dijkstra, K. D. B. (2006). Field guide to the dragonflies of Britain and Europe. Bloomsbury Publishing PLC.

Dolny, A., Sigutova, H., Ozana, S., \& Choleva, L. (2018). How difficult is it to reintroduce a dragonfly? Fifteen years monitoring Leucorrhinia dubia at the receiving site. Biological Conservation, 218, 110-117. https://doi.org/10.1016/j.biocon.2017.12.011

Essl, F., Dullinger, S., Genovesi, P., Hulme, P. E., Jeschke, J. M., Katsanevakis, S., Kühn, I., Lenzner, B., Pauchard, A., Pyšek, P., Rabitsch, W., Richardson, D. M., Seebens, H., van Kleunen, M., van der Putten, W. H., Vilà, M., \& Bacher, S. (2019). A conceptual framework for range-expanding species that track human-induced environmental change. BioScience, 69(11), 908-919. https://doi. org/10.1093/biosci/biz101

European Environment Agency (2015). State of nature in the EU - Results from reporting under the nature directives 2007-2012. European Environment and Agency.

Flenner, I., \& Sahlen, G. (2008). Dragonfly community re-organisation in boreal forest lakes: Rapid species turnover driven by climate change? Insect Conservation and Diversity, 1(3), 169-179. https://doi. org/10.1111/j.1752-4598.2008.00020.x

Giger, W. (2009). The Rhine red, the fish dead-the 1986 Schweizerhalle disaster, a retrospect and long-term impact assessment. Environmental Science and Pollution Research, 16, 98-111. https://doi.org/10.1007/ s11356-009-0156-y

Goertzen, D., \& Suhling, F. (2019). Urbanization versus other land use: Diverging effects on dragonfly communities in Germany. Diversity and Distributions, 25(1), 38-47. https://doi.org/10.1111/ddi.12820

Gregory, R. D., Skorpilova, J., Vorisek, P., \& Butler, S. (2019). An analysis of trends, uncertainty and species selection shows contrasting trends of widespread forest and farmland birds in Europe. Ecological Indicators, 103, 676-687. https://doi.org/10.1016/j.ecolind.2019.04.064

Hallmann, C. A., Foppen, R. P. B., van Turnhout, C. A. M., de Kroon, H., \& Jongejans, E. (2014). Declines in insectivorous birds are associated with high neonicotinoid concentrations. Nature, 511(7509), 341-343. https://doi.org/10.1038/nature13531

Hallmann, C. A., Sorg, M., Jongejans, E., Siepel, H., Hofland, N., Schwan, H., Stenmans, W., Müller, A., Sumser, H., Hörren, T., Goulson, D., \& de Kroon, H. (2017). More than 75 percent decline over 27 years in total flying insect biomass in protected areas. PLoS One, 12(10), e0185809. https://doi.org/10.1371/journal.pone.0185809

Hassall, C. (2015). Odonata as candidate macroecological barometers for global climate change. Freshwater Science, 34(3), 1040-1049. https:// doi.org/10.1086/682210

He, F., Zarfl, C., Bremerich, V., David, J. N. W., Hogan, Z., Kalinkat, G., Tockner, K., \& Jähnig, S. C. (2019). The global decline of freshwater megafauna. Global Change Biology, 25(11), 3883-3892. https://doi. org/10.1111/gcb.14753

Hering, D., Borja, A., Carstensen, J., Carvalho, L., Elliott, M., Feld, C. K., Heiskanen, A.-S., Johnson, R. K., Moe, J., \& Pont, D. (2010). The European Water Framework Directive at the age of 10: A critical review of the achievements with recommendations for the future. Science of the Total Environment, 408(19), 4007-4019. https://doi. org/10.1016/j.scitotenv.2010.05.031 
Hickling, R., Roy, D. B., Hill, J. K., Fox, R., \& Thomas, C. D. (2006). The distributions of a wide range of taxonomic groups are expanding polewards. Global Change Biology, 12(3), 450-455. https://doi. org/10.1111/j.1365-2486.2006.01116.x

Hickling, R., Roy, D. B., Hill, J. K., \& Thomas, C. D. (2005). A northward shift of range margins in British Odonata. Global Change Biology, 11(3), 502-506. https://doi.org/10.1111/j.1365-2486.2005.00904.x

Homburg, K., Drees, C., Boutaud, E., Nolte, D., Schuett, W., Zumstein, P., Ruschkowski, E., \& Assmann, T. (2019). Where have all the beetles gone? Long-term study reveals carabid species decline in a nature reserve in Northern Germany. Insect Conservation and Diversity, 12(4), 268-277. https://doi.org/10.1111/icad.12348

Isaac, N. J. B., van Strien, A. J., August, T. A., de Zeeuw, M. P., \& Roy, D. B. (2014). Statistics for citizen science: Extracting signals of change from noisy ecological data. Methods in Ecology and Evolution, 5(10), 1052-1060. https://doi.org/10.1111/2041-210x.12254

Jansen, F., Bonn, A., Bowler, D. E., Bruelheide, H., \& Eichenlberg, D. (2020). Moderately common plants show highest relative losses. Conservation Letters, 13(1), https://doi.org/10.1111/conl.12674

Jiguet, F., Gadot, A. S., Julliard, R., Newson, S. E., \& Couvet, D. (2007). Climate envelope, life history traits and the resilience of birds facing global change. Global Change Biology, 13(8), 1672-1684. https://doi. org/10.1111/j.1365-2486.2007.01386.x

Kalkman, V. J., Boudot, J. P., Bernard, R., De Knijf, G., Suhling, F., \& Termaat, T. (2018). Diversity and conservation of European dragonflies and damselflies (Odonata). Hydrobiologia, 811(1), 269-282. https://doi.org/10.1007/s10750-017-3495-6

Kéry, M., Guillera-Arroita, G., \& Lahoz-Monfort, J. J. (2013). Analysing and mapping species range dynamics using occupancy models. Journal of Biogeography, 40(8), 1463-1474. https://doi.org/10.1111/jbi.12087

Kéry, M., \& Royle, J. A. (2015). Applied hierarchical modeling in ecology: Analysis of distribution, abundance and species richness in $R$ and BUGS: Volume 1: Prelude and Static Models. Academic Press.

Kéry, M., Royle, J. A., Schmid, H., Schaub, M., Volet, B., Hafliger, G., \& Zbinden, N. (2010). Site-occupancy distribution modeling to correct population-trend estimates derived from opportunistic observations. Conservation Biology, 24(5), 1388-1397. https://doi. org/10.1111/j.1523-1739.2010.01479.x

Krieger, A., Fartmann, T., \& Poniatowski, D. (2019). Restoration of raised bogs-Land-use history determines the composition of dragonfly assemblages. Biological Conservation, 237, 291-298. https://doi. org/10.1016/j.biocon.2019.06.032

Macgregor, C. J., Williams, J. H., Bell, J. R., \& Thomas, C. D. (2019). Moth biomass increases and decreases over 50 years in Britain. Nature Ecology \& Evolution, 3(12), 1645-1649. https://doi.org/10.1038/ s41559-019-1028-6

Mauersberger, R., Brauner, O., Petzold, F., \& Krise, M. (2013). Die Libellenfauna des Landes Brandenburg. Naturschutz Und Landschaftspflege in Brandenburg, 22, 1-186.

Montero, P., \& Vilar, J. A. (2014). TSclust: An R Package for Time series clustering. Journal of Statistical Software, 62(1), 1-43.

Opitz, T., Achtziger, R., \& Lueg, L. (2019). Analysis of small water bodies and the occurrence and reproduction of amphibians in the Hospitaland Stadtwald of Freiberg during the dry year 2018. Freiberg Ecology Online, 5, 13-34.

Ott, J. (2010). Dragonflies and climate change - recent trends in Germany and Europe. BIORISK? Biodiversity and Ecosystem Risk Assessment, 5, 253-286.

Ott, J., Conze, K.-J., Günther, A., Mauersberger, R., Roland, H.-J., \& Suhling, F. (2015). Rote Liste und Gesamtartenliste der Libellen Deutschlands mit Analyse der Verantwortung, dritte Fassung, Stand Anfang 2012. Libellula Supplement, 14, 395-422.

Outhwaite, C. L., Chandler, R. E., Powney, G. D., Collen, B., Gregory R. D., \& Isaac, N. J. B. (2018). Prior specification in Bayesian occupancy modelling improves analysis of species occurrence data.
Ecological Indicators, 93, 333-343. https://doi.org/10.1016/j.ecoli nd.2018.05.010

Outhwaite, C. L., Gregory, R. D., Chandler, R. E., Collen, B., \& Isaac, N. J. B. (2020). Complex long-term biodiversity change among invertebrates, bryophytes and lichens. Nature Ecology \& Evolution, 4(3), 384392. https://doi.org/10.1038/s41559-020-1111-z

Outhwaite, C. L., Powney, G. D., August, T. A., Chandler, R. E., Rorke, S., Pescott, O. L., Harvey, M., Roy, H. E., Fox, R., Roy, D. B., Alexander, K., Ball, S., Bantock, T., Barber, T., Beckmann, B. C., Cook, T., Flanagan, J., Fowles, A., Hammond, P., ... Isaac, N. J. B. (2019). Annual estimates of occupancy for bryophytes, lichens and invertebrates in the UK, 1970-2015. Scientific Data, 6, 1970-2015. https://doi.org/10.1038/ s41597-019-0269-1

Paradis, E., \& Schliep, K. (2019). ape 5.0: An environment for modern phylogenetics and evolutionary analyses in R. Bioinformatics, 35(3), 526-528. https://doi.org/10.1093/bioinformatics/bty633

Petzold, F., \& Fritzlar, F. (2014). Basiserfassungen zur Libellenfauna - Landesweites Probestellennetz für ein Libellenmonitoring in Thüringen. Landschaftspflege Und Naturschutz in Thüringen, 51(1), 3-11.

Powney, G. D., Cham, S. S. A., Smallshire, D., \& Isaac, N. J. B. (2015). Trait correlates of distribution trends in the Odonata of Britain and Ireland. Peerj, 3, e1410. https://doi.org/10.7717/peerj.1410

Rapacciuolo, G., Ball-Damerow, J. E., Zeilinger, A. R., \& Resh, V. H. (2017). Detecting long-term occupancy changes in Californian odonates from natural history and citizen science records. Biodiversity and Conservation, 26(12), 2933-2949. https://doi.org/10.1007/s1053 1-017-1399-4

Rüppell, G. (1989). Kinematic analysis of symmetrical flight maneuvers of odonata. Journal of Experimental Biology, 144, 13-42.

Seibold, S., Gossner, M. M., Simons, N. K., Blüthgen, N., Müller, J., Ambarlı, D., Ammer, C., Bauhus, J., Fischer, M., Habel, J. C., Linsenmair, K. E., Nauss, T., Penone, C., Prati, D., Schall, P., Schulze, E.-D., Vogt, J., Wöllauer, S., \& Weisser, W. W. (2019). Arthropod decline in grasslands and forests is associated with landscape-level drivers. Nature, 574(7780), 671-674. https://doi.org/10.1038/s41586-019-1684-3

Suhling, I., \& Suhling, F. (2013). Thermal adaptation affects interactions between a range-expanding and a native odonate species. Freshwater Biology, 58(4), 705-714. https://doi.org/10.1111/fwb.12074

Termaat, T., van Grunsven, R. H. A., Plate, C. L., \& van Strien, A. J. (2015). Strong recovery of dragonflies in recent decades in The Netherlands. Freshwater Science, 34(3), 1094-1104. https://doi. org/10.1086/682669

Termaat, T., van Strien, A. J., van Grunsven, R. H. A., De Knijf, G., Bjelke, U., Burbach, K., Conze, K.-J., Goffart, P., Hepper, D., Kalkman, V. J., Motte, G., Prins, M. D., Prunier, F., Sparrow, D., van den Top, G. G., Vanappelghem, C., Winterholler, M., \& WallisDeVries, M. F. (2019). Distribution trends of European dragonflies under climate change. Diversity and Distributions, 25(6), 936-950. https://doi.org/10.1111/ ddi.12913

Thomas, G., Lorenz, A. W., Sundermann, A., Haase, P., Peter, A., \& Stoll, S. (2015). Fish community responses and the temporal dynamics of recovery following river habitat restorations in Europe. Freshwater Science, 34(3), 975-990. https://doi.org/10.1086/681820

Trockur, B. (2013). Bemerkenswertes und aktuelle Ergänzungen zur Libellenfauna des Saarlandes aus den Jahren 2002 bis 2011 (Insecta: Odonata). Abhandlungen Der Delattinia, 39, 79-154.

Valtonen, A., Hirka, A., Szocs, L., Ayres, M. P., Roininen, H., \& Csoka, G. (2017). Long-term species loss and homogenization of moth communities in Central Europe. Journal of Animal Ecology, 86(4), 730-738. https://doi.org/10.1111/1365-2656.12687

van Grunsven, R., Bos, G., \& Poot, M. (2020). Strong changes in Dutch dragonfly fauna. Agrion, 24(2), 134-138.

Van Klink, R., Bowler, D. E., Gongalsky, K. B., Swengel, A. B., Gentile, A., $\&$ Chase, J. M. (2020). Meta-analysis reveals declines in terrestrial 
but increases in freshwater insect abundances. Science, 368(6489), 417-420. https://doi.org/10.1126/science.aax9931

van Strien, A. J., Meyling, A. W. G., Herder, J. E., Hollander, H., Kalkman, V. J., Poot, M. J. M., Turnhout, S., van der Hoorn, B., van Strienvan Liempt, W. T. F. H., van Swaay, C. A. M., van Turnhout, C. A. M., Verweij, R. J. T., \& Oerlemans, N. J. (2016). Modest recovery of biodiversity in a western European country: The Living Planet Index for the Netherlands. Biological Conservation, 200, 44-50. https://doi. org/10.1016/j.biocon.2016.05.031

van Strien, A. J., Termaat, T., Groenendijk, D., Mensing, V., \& Kery, M. (2010). Site-occupancy models may offer new opportunities for dragonfly monitoring based on daily species lists. Basic and Applied Ecology, 11(6), 495-503. https://doi.org/10.1016/j.baae.2010.05.003

van Strien, A. J., van Swaay, C. A. M., \& Termaat, T. (2013). Opportunistic citizen science data of animal species produce reliable estimates of distribution trends if analysed with occupancy models. Journal of Applied Ecology, 50(6), 1450-1458. https://doi. org/10.1111/1365-2664.12158

van Swaay, C. A. M., Nowicki, P., Settele, J., \& van Strien, A. J. (2008). Butterfly monitoring in Europe: Methods, applications and perspectives. Biodiversity and Conservation, 17(14), 3455-3469. https://doi. org/10.1007/s10531-008-9491-4

Vörösmarty, C. J., McIntyre, P. B., Gessner, M. O., Dudgeon, D., Prusevich, A., Green, P., Glidden, S., Bunn, S. E., Sullivan, C. A., Liermann, C. R., \&
Davies, P. M. (2010). Global threats to human water security and river biodiversity. Nature, 467(7315), 555-561. https://doi.org/10.1038/ nature09440

\section{BIOSKETCH}

The co-author team are part of the sMon project (https://www. idiv.de/en/smon.html) that aims to use heterogeneous data to improve knowledge of large-scale biodiversity change in Germany.

\section{SUPPORTING INFORMATION}

Additional supporting information may be found online in the Supporting Information section.

How to cite this article: Bowler DE, Eichenberg D, Conze K-J, et al. Winners and losers over 35 years of dragonfly and damselfly distributional change in Germany. Divers Distrib. 2021;27:1353-1366. https://doi.org/10.1111/ddi.13274 